\title{
Effects of adrenocorticotropic hormone on appetitive discrimination performance in rats
}

\author{
WILLIAM L. STOLLER and RITA A. V. STOLLER \\ Indiana University, Kokomo, Indiana
}

\begin{abstract}
Albino rats received subcutaneous injections of either adrenocorticotropic hormone (ACTH, 50 U.S.P. units $/ \mathrm{kg}$ ) or isotonic saline following training sessions on a visual discrimination task for which leverpressing in the presence of a cuelight was reinforced with food. Upon attainment of criterion, half of the subjects under each training treatment received injections of ACTH prior to extinction sessions, while half received the saline. Acquisition performance of the rats receiving ACTH was comparable to that of their saline controls. The animals that received the same injection treatment for the two phases of the study responded more during extinction than did the animals for which treatment was changed. The hormone had no detectable effect on activity of the animals in an open field, but reduced body weight in relation to the control level. The extinction results are discussed in terms of a possible storage or cue-function state dependency determined by circulating ACTH.
\end{abstract}

Evidence has accumulated showing that adrenocorticotropic hormone (ACTH) and some closely related peptides can modify behavior in aversive learning paradigms. In the active avoidance paradigm, for example, administration of ACTH, ACTH 1-10, ACTH 5-10, or ACTH 1-24 to rats during extinction trials has resulted in less rapid rates of extinction (De Wied, 1966). ACTH 4-10 treatment has restored the impaired shuttlebox acquisition of hypophysectomized rats, whereas cessation of treatment has resulted in a progressive decrease in avoidance performance of such animals (Bohus, Gispen, \& De Wied, 1973). Izquierdo and Dias (1983a) found that posttraining administration of ACTH 1-24 caused retrograde amnesia for a step-down inhibitory avoidance task in which training footshock was high, whereas it produced memory facilitation for a closely related step-down task in which training footshock was low.

ACTH and some of its molecular fragments appear capable of playing an important role in certain appetitive paradigms. For a leverpress response reinforced with water, injection of ACTH prior to acquisition sessions has increased responding early in extinction (Guth, Levine, \& Seward, 1971). Garrud, Gray, and De Wied (1974) found that ACTH, ACTH 4-10, and ACTH 1-24, when injected during extinction, retarded the extinction of a running response in rats that had been trained under food reinforcement. O'Reilly, Coleman, and $\mathrm{Ng}$ (1983) observed that posttrial administration of ACTH 4-10 facilitated acquisition of a food-reinforced maze task. However, Miller

This study was supported by the Melvin L. Goldstein Fund for Research in Experimental Psychology and by funds received from the Office of Research and Advanced Studies at Indiana University. Requests for reprints should be sent to W. L. Stoller, Indiana University at Kokomo, 2300 South Washington Street, P.O. Box 9003, Kokomo, IN 46904-9003. and Caul (1973), also using rats, reported that ACTH had no effect of any kind on acquisition or reversal learning of a food-rewarded black-white discrimination.

Observations on the influence of posttrial injections of ACTH to animals trained in a one-trial inhibitory avoidance task and tested for retention $24 \mathrm{~h}$ later support the view that ACTH may modulate memory storage processing of recent information (Gold \& Van Buskirk, 1976a, 1976b). At least for some aversive paradigms, it appears that both retention performance and extinction performance depend in part on the relationship between the posttraining and testing levels of circulating ACTH (Izquierdo \& Dias, 1983b). In view of these considerations and results such as those cited above, we sought to obtain additional information on the generality of ACTH influences on appetitive behavior. Specifically, the purpose of the present study was to (1) examine the possibility that postsession administration of ACTH might affect the acquisition of a food-reinforced visual discrimination, and (2) investigate the possible effects of postsession training injections and presession extinction injections of ACTH on performance of the previously food-reinforced response during extinction in the presence of the discriminative stimulus of the training phase. Observations on discriminative behavior were supplemented by measurements of activity in an open field and body weight.

\section{METHOD}

\section{Subjects}

Thirty-two male albino rats obtained from the Harlan Sprague Dawley Company (Indianapolis, IN) were used. The animals were about 120 days old at the beginning of experimentation and had no previous experimental history. They were maintained in individual cages on a 13:11-h light:dark cycle with light onset at 6:30 a.m. 


\section{Apparatus}

A $27.9 \times 20.3 \times 20.3 \mathrm{~cm}$ (inside dimensions) operant chamber housed in a sound-attenuation box was used in training and testing the animals. The front and rear walls of the chamber were constructed from $0.1-\mathrm{cm}$ stainless steel; the sides and hinged top were made of 0.6- and 0.4-cm Plexiglas, respectively. The floor consisted of $0.5-\mathrm{cm}$ stainless steel rods spaced $1.6 \mathrm{~cm}$ center to center. A single lever, which extended $5.1 \mathrm{~cm}$ across the front wall and was $0.1 \mathrm{~cm}$ thick, projected $2.5 \mathrm{~cm}$ into the chamber. The lever was $6.5 \mathrm{~cm}$ above the grid floor and required a force of $15 \mathrm{~g}(0.3-\mathrm{cm}$ excursion) to activate an attached microswitch. A cuelight was centered $6.5 \mathrm{~cm}$ above the lever. Reinforcements for leverpressing, consisting of single $45-\mathrm{mg}$ food pellets (Bio-Serv), were delivered from a pellet dispenser into a food cup located in the lower right corner of the front wall, $2.2 \mathrm{~cm}$ above the floor. Leverpresses were recorded on a manually resettable four-digit counter.

An unpainted box with a $91.3 \times 91.3 \mathrm{~cm}$ floor and $59.8-\mathrm{cm}$-high sides (inside dimensions) was used in obtaining open-field activity measures for the animals. The box was open at the top and had a floor and sides made of $1.3-\mathrm{cm}$ plywood. The floor was divided into nine equal squares. A shielded $150-\mathrm{W}$ lamp about $0.5 \mathrm{~m}$ from the box provided background illumination when activity was being measured.

\section{Procedure}

There were 8 randomly assigned subjects for each of four specific treatments: training ACTH and extinction ACTH (ACTHACTH), training ACTH and extinction saline (ACTH-saline), training saline and extinction ACTH (saline-ACTH), and training saline and extinction saline (saline-saline). During the course of the experiment, each of the animals received subcutaneous injections of either ACTH (50 U.S.P. units/kg, H.P. Acthar Gel, 40 U.S.P. units $/ \mathrm{ml}$, Armour Pharmaceutical Co.) or an equivalent volume of isotonic saline according to the treatment paradigm. The operant methodology was based partially on a procedure used by Schwartzbaum, Kellicutt, Spieth, and Thompson (1964).

Over a 6-day period, the animals were adapted to a 20 -h fooddeprivation schedule that allowed free access to food for $2 \mathrm{~h}$ per day. During the subsequent training sessions, they received additional food as a consequence of reinforced performance, but a supplemental feeding procedure was not used in the study. Following the adaptation period, the animals were trained or tested between 10:00 a.m. and 1:15 p.m. every other day for the remainder of the experiment. For a given animal, there was one session on each day of training or testing.

Each animal was given 8-min sessions of preliminary training, during which it received food reinforcement for leverpressing according to a fixed-ratio schedule requiring five responses per reinforcement. During these sessions, intervals of cuelight on and cuelight off occurred randomly, and reinforcement was not contingent on the presence of the cuelight. Discrimination training began for each animal after four such sessions; depending on its group assignment, an animal received an injection of either ACTH or saline immediately after its session in the operant chamber. $S+$ was cuelight on, and $S-$ was cuelight off. For $S+$, leverpressing was reinforced according to the 5:1 reinforcement schedule, whereas for $S-$, leverpressing was never reinforced. $S-$ and $S+$ were each presented twice for periods of 2 min during the 8-min discrimination sessions. The order of presentation was random. An animal received discrimination training until (1) the mean number of responses per minute during $\mathbf{S}+$ was at least three times as great as that during $S-$ over eight consecutive sessions, and (2) this ratio was attained for at least five of the eight sessions. Criterion performance was followed by two 8-min extinction sessions during which the stimulus that had been the $S+$ of the training sessions was continuously present; reinforcement was never given at any time during an extinction session. Depending on its specific treat- ment, an animal received an injection of either ACTH or saline $11 / 4 \mathrm{~h}$ before the session.

Following the extinction phase of the study, four sessions were devoted to the assessment of activity beginning $11 / 4 \mathrm{~h}$ after ACTH or saline injection, according to the animal's treatment during extinction. An animal was placed on the floor of the plywood box and was then allowed to move about the enclosure freely for $15 \mathrm{~min}$. An observer who was unaware of the treatment to which the rat had been assigned recorded the number of squares entered by the animal during successive 5-min periods. An animal was scored as having entered a given square if it placed all four feet within the square. All the subjects had at least $4 \mathrm{~h}$ of prior experience in the box before the activity measurements.

Analyses of variance (ANOVAs) were used in the statistical evaluation of the data on acquisition, extinction, activity, and weight. A two-tailed Mann-Whitney $U$ test and two-tailed $t$ tests, in addition to the ANOVAs, were applied to data on acquisition and extinction, respectively.

\section{RESULTS}

Figure 1 shows discrimination performance in terms of percentage changes in response rate under both $\mathrm{S}+$ and $\mathrm{S}$ - for the animals that received postsession injections of ACTH $(n=16)$ and the corresponding controls that were given saline $(n=16)$. Under $S+$, responding of

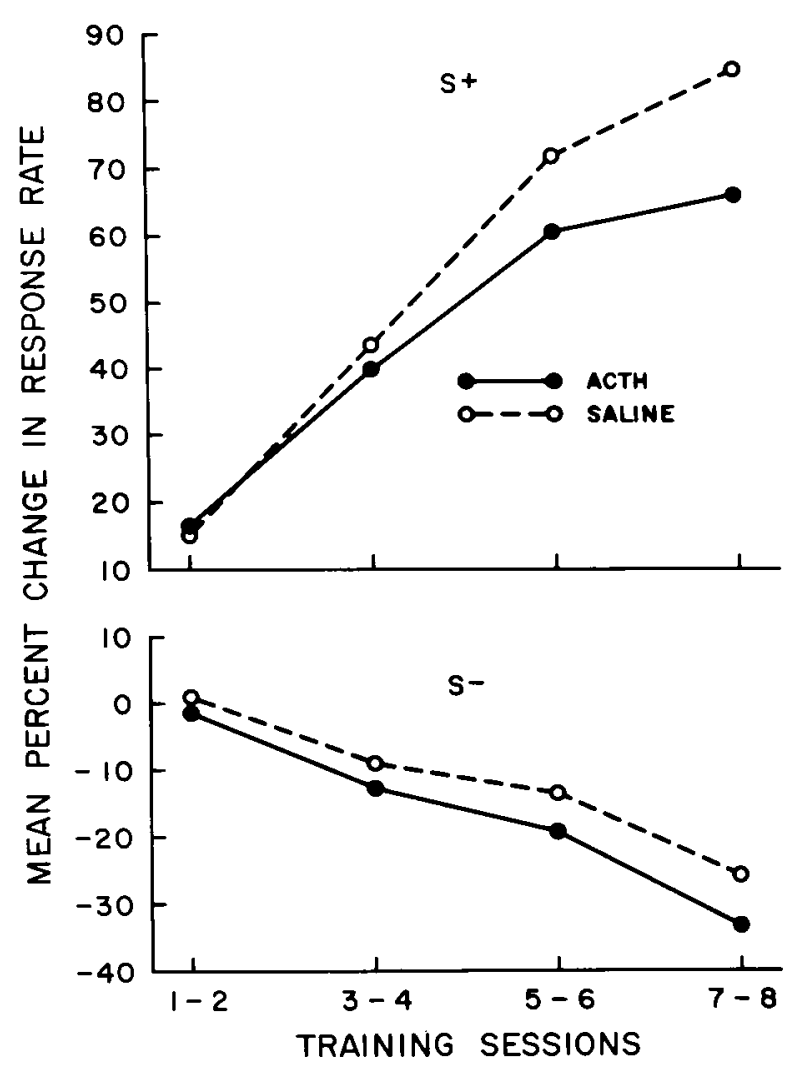

Figure 1. Changes in response rate for the discrimination task under conditions of reinforcement $(S+)$ and nonreinforcement $(S-)$. Baseline was provided by performance during immediateły preceding two noncontingent reinforcement sessions. 
both groups increased, whereas under $\mathrm{S}-$, it decreased. Under neither S+ nor S- did responding of the ACTH group differ significantly from that of the saline group ( $F$ tests, $p s>.05$ ). For both $S+$ and $S-$, the session's main effect was significant $[F(3,90)=34.91, p<.0001$, and $F(3,90)=14.61, p<.0001$, respectively], but the treatments $\times$ sessions interactions for each were nonsignificant ( $F$ tests, $p s>.05$ ). The ACTH and saline groups did not differ significantly in terms of the number of sessions required to reach criterion performance ( $U=157$, $p>.05$ ).

Figure 2 summarizes performance of the four specific treatment groups (ACTH-ACTH, ACTH-saline, salineACTH, and saline-saline) during each of the two extinction sessions. For Session 1, response rates generally decreased over the extinction interval. An ANOVA on data over the entire interval showed a significant main effect of minutes $[F(3,84)=7.88, p<.001]$ and nonsignificant main effects for training treatments and extinction treatments $(F$ tests, $p s>.05$ ). The training treatments $x$ extinction treatments and training treatments $\times$ minutes interactions were significant $[F(1,28)=7.66, p<.01$, and $F(3,84)=4.13, p<.01$, respectively], but the extinction treatments $\times$ minutes interaction as well as the three-way interaction were nonsignificant ( $F$ tests, $p s>$ $.05)$. Percentage changes in response rate over the entire 8-min session were significantly below baseline level for all four groups $(t$ tests, $p \mathrm{~s}<.0001)$.

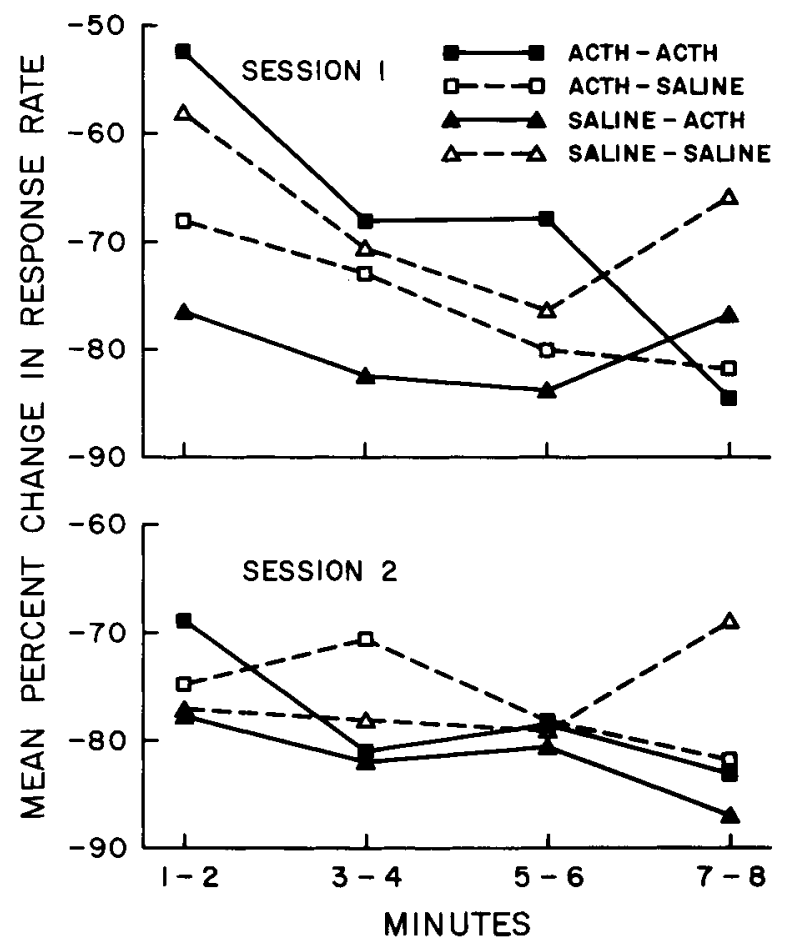

Figure 2. Changes in response rate for the discrimination task during each of two extinction sessions. Baseline was provided by performance under $\mathrm{S}+$ during the last five preextinction sessions.

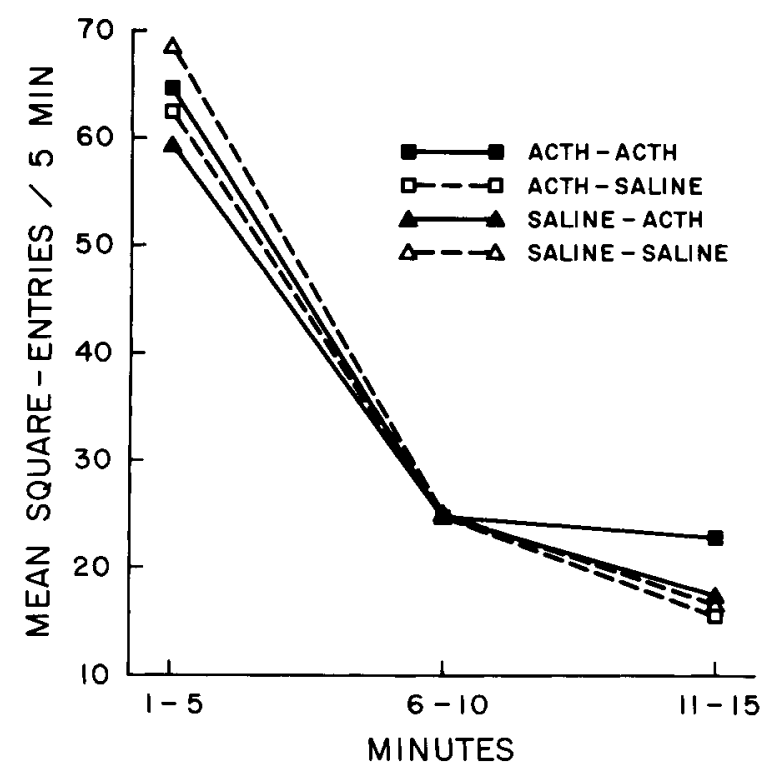

Figure 3. Activity averaged over four sessions following Extinction Session 2.

The overall Session 1 means were $-68.28 \%,-75.75 \%$, $-79.91 \%$, and $-67.75 \%$ for the ACTH-ACTH, ACTHsaline, saline-ACTH, and saline-saline groups, respectively. Orthogonal contrasts performed on these means showed that the average response level of the ACTHACTH and saline-saline groups was significantly higher than the average response level of the ACTH-saline and saline-ACTH groups $[F(1,28)=7.66, p<.01]$, whereas the difference between the ACTH- ACTH and saline-saline groups as well as the difference between the ACTH-saline and saline-ACTH groups was nonsignificant $(F \mathrm{~S}<1.00)$.

For Session 2, as for Session 1, percentage changes in response rate over the entire 8-min extinction interval were significantly below baseline level for all four groups ( $t$ tests, $p \mathrm{~s}<.0001$ ). An ANOVA yielded no significant main effects or interactions ( $F$ tests, $p s>.05$ ).

Figure 3 summarizes data on activity of the four groups averaged over the four sessions following Extinction Session 2 . The activity of all the groups decreased over the 15-min period. An ANOVA showed a significant main effect of minutes $[F(2,56)=279.74, p<.0001]$ and nonsignificant main effects for training treatments and testing treatments, as well as nonsignificant interactions ( $F$ tests, $p s>.05$ ).

Figure 4 summarizes data on weight changes for the ACTH-injected animals and their saline-injected controls over the first eight discrimination training sessions. The figure shows that the weight of the control group progressively increased over the sessions, whereas the weight of the ACTH-treated group was essentially constant. An ANOVA yielded significant main effects for treatments and sessions, as well as a significant treatments $\times$ ses- 


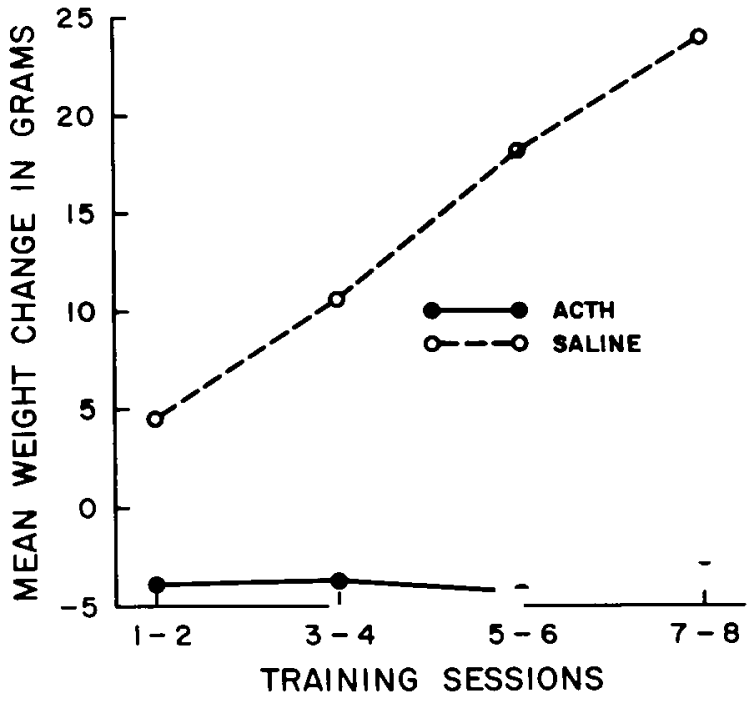

Figure 4. Changes in body weight relative to weight at the beginning of the first discrimination training session.

sions interaction $[F(1,30)=125.94, F(3,90)=69.37$, and $F(3,90)=58.08$, respectively, $p s<.0001$ ]. From the first through the fourth block of two sessions, the control mean was significantly greater than the mean of the ACTH-treated group $[F(1,52)=20.65, F(1,52)=$ $59.61, F(1,52)=148.38$, and $F(1,52)=206.71$, respectively, $p \mathrm{~s}<.0001$ ].

\section{DISCUSSION}

The data of the present study support the view that, in rats, performance during extinction of a visual-discrimination response previously reinforced with food depends at least in part on the relationship between the level of circulating ACTH (exogenous plus endogenous ACTH) following training sessions and the testing level of circulating ACTH (cf. Izquierdo \& Dias, 1983b). At the same time, there was no evidence indicating that postsession injections of ACTH affected rate of discrimination acquisition, or that training treatment or injections of ACTH prior to extinction sessions had a simple overall effect on performance during extinction. In addition, ACTH had no detectable effect on the activity of the animals in an open field, but reduced body weight in relation to the control level.

The comparability of the acquisition performance of the ACTH-treated animals and that of the saline-treated controls is consistent with the results of Miller and Caul (1973) on appetitive discrimination learning in the rat. These investigators suggested that ACTH may support very simple repetitive performance in some special appetitive situations, but emphasized that their results provided no support for a facilitative effect of ACTH on either learning or performance in an appetitive task requiring a discrimination from the animal. It is to be noted that, although they administered presession injections to the animals, the level of circulating ACTH could be expected to be elevated for some time following completion of the session.

In the present study, the groups tested under the same injection treatments that were used for training responded more during the first extinction session than did the groups for which the treatments were changed. At the same time, the former two groups as well as the latter two displayed comparable overall response rates during extinction. These results can be interpreted in terms of a symmetrical retrograde state dependency resembling that discussed by Chute and Wright (1973) for a one-trial passive avoidance task in which rats received sodium pentobarbital intravenously following response acquisition. Their data supported the hypothesis that for transfer of training from acquisition to the retention test to be possible, information storage following acquisition trials and information retrieval during retention trials must occur under equivalent central nervous system states. This storage hypothesis contrasts the alternate stimulus hypothesis considered by Chute and Wright, according to which state-dependent learning is a special case of stimulus generalization. Considering the results of our study in relation to the methodology used, which permitted the level of circulating ACTH during testing to approximate rather than precisely equal that during training, it appears useful to regard such a storage-based state dependency as essentially a graded phenomenon.

On the other hand, if it is assumed that the level of circulating ACTH or some associated substance or substances present immediately after a learning experience is capable of providing a component of the training memory, then a cue-function state dependency interpretation can be applied to the results of the present study as well as to those of at least some studies using aversive paradigms (Izquierdo \& Dias, 1983b; Izquierdo \& Dias, 1985; Izquierdo \& Netto, 1985). Izquierdo and Dias (1985), in a step-down inhibitory avoidance study that included the administration of ACTH 1-24 and epinephrine to rats shortly after training or prior to testing, obtained evidence supporting the hypothesis that learning of the avoidance task depends on the state induced by $\beta$-endorphin after training, and that it would be dissociated under normal conditions because this peptide is normally not released during test sessions. These investigators pointed out that ACTH injections, as well as injections of epinephrine, release brain $\beta$-endorphin (Carrasco et al., 1982), and that the influences of these substances on retrieval may be explained by the release of $\beta$-endorphin and consequent changes in the extent to which the posttraining and testing $\beta$-endorphin levels agree. However, the results of a study by Izquierdo and McGaugh (1987), in which mice were trained in a step-through inhibitory avoidance task, provide evidence for a state dependency on epinephrine as well as an opioid state dependency, presumably mediated by $\beta$-endorphin. This suggests that an ACTH state depen- 
dency may be operative in at least some aversive paradigms. Such a state dependency could also influence appetitively motivated behavior for which the learning experience has involved a period of stress following reinforcement.

The results of studies on the reversibility of experimentally induced retrograde amnesia are consistent with the view that there is an ACTH state-dependent mechanism in which ACTH provides a cue for retrieval of the target memory (Mactutus, Smith, \& Riccio, 1980; Rigter \& Van Riezen, 1975; Rigter, Van Riezen, \& De Wied, 1974; Santucci, Riccio, \& Treichler, 1989). For example, Santucci et al. trained rats on a passive avoidance task, administered hypothermia as the amnestic agent, and shortly before testing gave treatments that were known to be effective in reversing hypothermia-induced memory loss. When ACTH release was suppressed by injecting dexamethasone before training or testing, a diminished recovery was observed, in agreement with the view that memory recovery increases with increasing congruency between the ACTH state present shortly after training and that at testing.

Thus, it appears possible to interpret the results of the present study in terms of an ACTH state dependency and a state dependency on $\beta$-endorphin. Even though some release of brain $\beta$-endorphin might occur during a training session (Izquierdo et al., 1984), postsession injection of ACTH at the dosage used in our study would presumably induce a substantial increase in its level. In testing, presession injections of ACTH given to animals that had received ACTH after training would serve to make the levels of ACTH and $\beta$-endorphin agree more closely with those following training, thereby improving performance by providing relevant cues in the test situation. The greater the degree of consistency between the internal cues of the training and testing situations, the better would be the performance. The finding that ACTH 4-10, which has virtually no corticotropic activity, can diminish retrograde amnesia (Rigter \& Van Riezen, 1975; Rigter et al., 1974) suggests that the effects of ACTH administration in the current study are at least partially independent of the adrenal cortex and are traceable to part, or all, of the 4-10 amino acid sequence.

The depressive effect of ACTH on the weight of the animals, presumably due to altered protein metabolism (Cannon, Frazier, \& Hughes, 1956), did not appear to be associated with any impairment in their general health. An informal examination of weight data gathered during the entire experiment indicated that termination of the hormone injections was followed by immediate and substantial weight gains.

\section{REFERENCES}

Bohus, B., GisPEN, W. H., \& DE Wied, D. (1973). Effect of lysine vasopressin and ACTH 4-10 on conditioned avoidance behavior of hypophysectomized rats. Neuroendocrinology, 11, 137-143.

Cannon, P. R., Frazier, L. E., \& Hughes, R. H. (1956). The influ- ence of cortisone upon protein metabolism. A.M.A. Archives of Pathology, 61, 271-279.

Carrasco, M. A., Dias, R. D., Perry, M. L. S., Wofchuk, S. T., SouzA, D. O., \& IzQuiERDo, I. (1982). Effect of morphine, ACTH, epinephrine, Met-, Leu- and des-Tyr-Met-enkephalin on $\beta$-endorphinlike immunoreactivity of rat brain. Psychoneuroendocrinology, 7, 229-234.

Chute, D. L., \& Wright, D. C. (1973). Retrograde state dependent learning. Science, 180, 878-880.

DE WIED, D. (1966). Inhibitory effect of ACTH and related peptides on extinction of conditioned avoidance behavior in rats. Proceedings of the Society for Experimental Biology \& Medicine, 122, 28-32.

Garrud, P., Gray, J. A., \& DE WIED, D. (1974). Pituitary-adrenal hormones and extinction of rewarded behaviour in the rat. Physiology \& Behavior, 12, 109-119.

GolD, P. E., \& VAN BUSKIRK, R. (1976a). Effects of posttrial hormone injections on memory processes. Hormones \& Behavior, 7, 509-517.

GoLD, P. E., \& VAN BUSKIRK, R. (1976b). Enhancement and impairment of memory processes with post-trial injections of adrenocorticotrophic hormone. Behavioral Biology, 16, 387-400.

Guth, S., Levine, S., \& Seward, J. P. (1971). Appetitive acquisition and extinction effects with exogenous ACTH. Physiology \& Behavior, 7, 195-200.

IzQuiERDO, I., \& DIAS, R. D. (1983a). Effect of ACTH, epinephrine, $\beta$-endorphin, naloxone, and of the combination of naloxone or $\beta$ endorphin with ACTH or epinephrine on memory consolidation. Psychoneuroendocrinology, 8, 81-87.

IzQuierdo, I., \& Dias, R. D. (1983b). Memory as a state dependent phenomenon: Role of ACTH and epinephrine. Behavioral \& Neural Biology, 38, 144-149.

IzquiERDo, I., \& DiAs, R. D. (1985). Influence on memory of posttraining or pre-test injections of ACTH, vasopressin, epinephrine, and $\beta$-endorphin, and their interaction with naloxone. Psychoneuroendocrinology, 10, 165-172.

IzQUIERDO, I., \& MCGAUGH, J. L. (1987). Retention impairment by posttraining epinephrine: Role of state dependency and of endogenous opioid mechanisms. Behavioral Neuroscience, 101, 778-781.

IzQuiERDO, I., \& NETTO, C. A. (1985). Factors that influence test session performance measured 0,3 , or $6 \mathrm{~h}$ after inhibitory avoidance training. Behavioral \& Neural Biology, 43, 260-273.

Izquierdo, I., Souza, D. O., Dias, R. D., Perry, M. L. S., CarRAsCo, M. A., VolKmer, N., \& NetTo, C. A. (1984). Effect of various behavioral training and testing procedures on brain $\beta$-endorphinlike immunoreactivity and the possible role of $\beta$-endorphin in be havioral regulation. Psychoneuroendocrinology, 9, 381-389.

Mactutus, C. F., Smith, R. L., \& Riccio, D. C. (1980). Extending the duration of ACTH-induced memory reactivation in an amnesic paradigm. Physiology \& Behavior, 24, 541-546.

Miller, R. E., \& CAUL, W. F. (1973). Effect of adrenocorticotropic hormone on appetitive discrimination learning in the rat. Physiology \& Behavior, 10, 141-143.

O'Reilly, H. M., Coleman, G. J., \& NG, K. T. (1983). The role of adrenocorticotropin and norepinephrine in appetitive learning in the rat. Physiology \& Behavior, 30, 253-258.

RigTER, H., \& VAN RIEZEN, H. (1975). Anti-amnesic effect of ACTH 4-10: Its independence of the nature of the amnesic agent and the behavioral test. Physiology \& Behavior, 14, 563-566.

Rigter, H., VAN Riezen, H., \& De Wied, D. (1974). The effects of $\mathrm{ACTH}$ - and vasopressin-analogues on $\mathrm{CO}_{2}$-induced retrograde amnesia in rats. Physiology \& Behavior, 13, 381-388.

Santucci, A. C., Riccio, D. C., \& Treichler, F. R. (1989). Role of ACTH in recovery from retrograde amnesia induced by hypothermia in rats. Behavioral Neuroscience, 103, 1267-1275.

Schwartzbaum, J. S., KellicutT, M. H., Spieth, T. M., \& Thompson, J. B. (1964). Effects of septal lesions in rats on response inhibition associated with food-reinforced behavior. Journal of Comparative \& Physiological Psychology, 58, 217-224.

(Manuscript received January 7, 1993; revision accepted for publication August 4, 1993.) 